\title{
Linkage analysis of infantile pyloric stenosis and markers from chromosome 9q11-q33: no evidence for a major gene in this candidate region
}

\author{
E Chung, R Coffey, K Parker, P Tam, M E Pembrey, R M Gardiner
}

Department of Paediatrics, The Rayne Institute, University College London Medical

School, 5 University Street, London WC1E 6JJ, UK. E Chung

K Parker

R M Gardiner

Mothercare

Department of

Clinical Genetics and

Fetal Medicine,

Institute of Child

Health, 30 Guilford

Street, London

WC1N 1EH, UK.

R Coffey

M E Pembrey

Nuffield Department of Surgery, John

Radcliffe Hospital,

Headington, Oxford

OX3 9DU, UK.

P Tam

Correspondence to

Dr Chung.

Received 13 October 1992. Revised version accepted 26 November 1992.

\begin{abstract}
A genetic component in the aetiology of infantile pyloric stenosis (PS) is well established. Segregation analysis is compatible with a multifactorial sex modified threshold model of inheritance but a major gene of low penetrance has not been excluded. PS has been reported to occur in $57 \%$ (four of seven) of cases with duplication of chromosome 9q11-q33. Twenty families with PS were studied using genetic markers at loci D9S55, D9S111，D9S15，D9S12，D9S56，D9S59, and $A S S$ from this region of chromosome 9. Pairwise lod scores of -2 were obtained with all these markers at recombination fractions greater or equal to 0.04 under both autosomal dominant and autosomal recessive models of inheritance. This provides evidence against the existence of a major locus predisposing to PS within chromosome 9q11-q33. (f Med Genet 1993;30:393-5)
\end{abstract}

Infantile pyloric stenosis (PS) is the commonest condition requiring surgical intervention in the first year of life. Its incidence is estimated to be 1 to $5 / 1000$ live births in Britain. ${ }^{12}$ Mortality was high until successful treatment by pyloromyotomy was developed by Rammstedt in 1911. Clinically it is characterised by projectile vomiting, visible gastric peristalsis, and a palpable pyloric tumour. Diagnosis is usually made clinically, supported on occasion by examination with ultrasound or barium contrast.

The aetiology of PS is entirely unknown though both genetic and environmental factors have been implicated. Its familial incidence was first reported by Cockayne and Penrose. ${ }^{34}$ This has been confirmed by subsequent family studies $^{25-7}$ but the exact inheritance mechanism has not been accurately defined. ${ }^{4-9}$ Segregation analysis is best explained by a multifactorial sex modified threshold model of inheritance, ${ }^{8-10}$ but it is compatible with a single major dominant gene of low penetrance with a multifactorial background. ${ }^{8112}$ The nature of the environmental factors concerned has remained unclear.

PS has been described in association with Smith-Lemli-Opitz syndrome and various chromosomal disorders, including Edwards's syndrome (trisomy 18), Down's syndrome (trisomy 21), and Turner's syndrome (XO). Chromosome 9 is suspected as a possible location of a PS locus because of the reported association of PS and duplication of chromosome $9 \mathrm{q} 11-\mathrm{q} 33 .{ }^{13-15} \mathrm{PS}$ was reported to occur in four of seven $(57 \%)$ of the cases with this duplication. ${ }^{16}$ Association of a phenotype with chromosomal duplication can be a guide to the location of causative gene loci, as illustrated by the identification of a locus for familial $\mathrm{Alz}$ heimer's disease on chromosome $21 .^{1718}$ Chromosome 9 is therefore a candidate region for the location of a gene predisposing to PS.

The existence of a comprehensive high resolution map of the human genome has rendered disease with complex inheritance amenable to linkage analysis. Following ascertainment of a suitable family resource, we are undertaking a systematic genome search to identify any major gene predisposing to PS by linkage analysis. The strategy involves analysis of candidate regions such as chromosome $9 \mathrm{q}$ in the first instance. We present the results of linkage analysis of 20 families and seven markers from this region of chromosome 9.

\section{Materials and methods}

FAMILIES

Twenty families with multiple members affected with PS were ascertained from a variety of sources, including families of probands identified in previous studies such as those of Carter ${ }^{8}$ Blood was obtained for DNA studies from 207 family members, 65 of whom were affected (46 males, 19 females). At least three affected subjects existed in 13 of the 20 families (figure). Diagnosis of PS was made according to standard criteria. It was confirmed at laparotomy in all but five of the affected subjects; these five were treated medically. One was diagnosed clinically and confirmed by barium studies. The other four were diagnosed on clinical examination alone. They belong to family 7 in which there are a total of five affected subjects in over two generations.

\section{DNA STUDIES}

Genomic DNA was extracted from leucocytes using a salt precipitation technique. ${ }^{19}$ Family members were phenotyped at $(\mathrm{CA})_{\mathrm{n}}$ repeat microsatellite marker loci on human chromosome 9: D9S55, D9S111, D9S15, D9S12, $D 9 S 56, D 9 S 59$, and $A S S$. Alleles at these loci were amplified using the polymerase chain reaction (PCR). Products were separated by $6 \%$ polyacrylamide gel electrophoresis and detected by autoradiography. ${ }^{20}$ 
Family 1
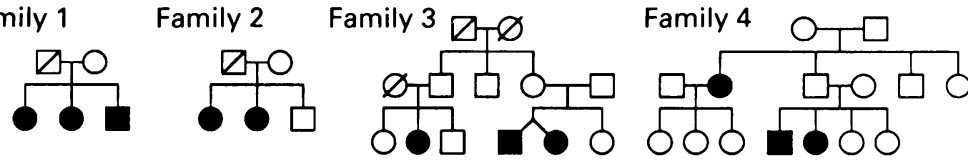

Family 5
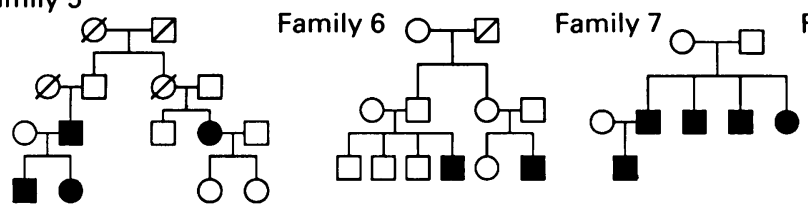

Family 8

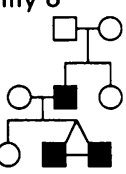

Family 9
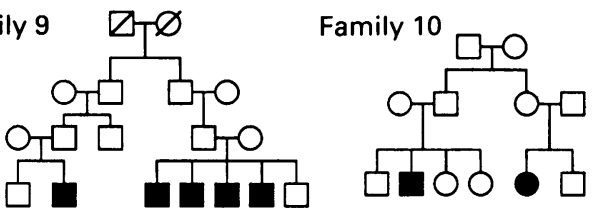

Family 11

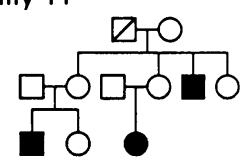

Family 13

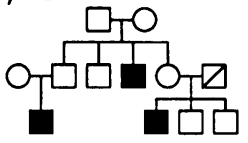

Family 14

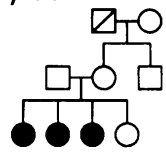

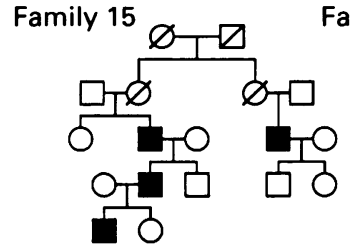

Family 18

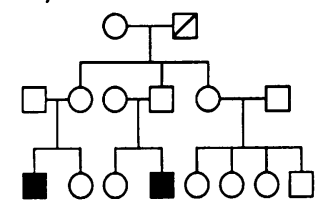

Family 19

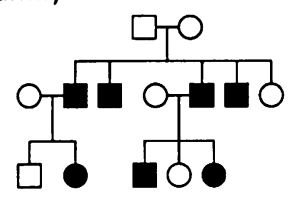

Family 17

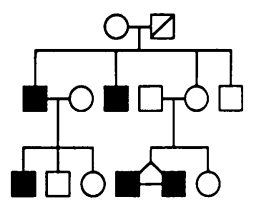

Family 20

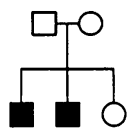

Pedigrees segregating for PS studied with markers on chromosome 9.

Seven markers on chromosome 9 were examined for linkage. The map used in the chromosome 9 analysis was from Povey et $a l^{2122}$ and Kwiatkowski et al. ${ }^{23}$

\section{LINKAGE ANALYSIS}

The MLINK subprogram of the LINKAGE (version 5.03) computer package was used to carry out the linkage analysis. Pairwise lod scores were calculated under two models of inheritance. The disease allele frequency was set equal to 0.002 for the autosomal dominant (AD) model and 0.05 for the autosomal recessive (AR) model. For both models, a phenocopy rate of 0.002 and sex specific penetrance values of 0.60 for male and 0.15 for female were used.

The data were analysed by using only affected subjects (that is, at risk family and married in family members were coded as unknown with respect to PS disease status) in the analysis. This eliminated any phenotypic information contributed by these subjects whose genotype with respect to PS was uncertain, but it maintained their genetic marker data for reconstructive and phase information.

Evidence of heterogeneity was sought by the Admixture test using the HOMOG program. ${ }^{24}$

\section{Results}

Pairwise lod scores between the PS trait and the seven marker loci are shown in the table. The recombination fractions at which lod score $=-2$ are also shown. Family 8 was uninformative for all the seven markers and family 7 and 20 were uninformative for locus D9S59.

The pairwise lod score was -2 at $\theta$ greater or equal to 0.04 for all marker loci. Our data provide evidence against the existence of a major locus predisposing to IHPS over the whole region from $D 9 S 55$ (9p12) to $A S S$ (9q34.1) for the AD model. For the AR model, the area of exclusion did not include regions of $5 \mathrm{cM}$ between loci D9S56 and D9S59 and between loci $D 9 S 59$ and $A S S$.

Results of the HOMOG analysis showed no evidence of heterogeneity (data not shown).

\section{Discussion}

The genetic basis of PS has been extensively investigated since its familial occurrence was first reported by Cockayne and Penrose ${ }^{34}$ over 50 years ago. A genetic contribution to its aetiology has been firmly established, but neither the exact mechanism of inheritance nor the gene products involved have been elucidated.

New methods for the investigation of inherited diseases known only by their phenotype, so called linkage analysis and 'positional cloning' strategies, have allowed major advances in our understanding of single gene disorders such as cystic fibrosis and Duchenne muscular dystrophy. However, most common familial human diseases, including PS, show complex inheritance. Application of linkage analysis to these complex traits raises numerous difficulties which have been widely discussed. ${ }^{2425}$

Several features of PS render it potentially more tractable to linkage analysis than other diseases with complex inheritance. The condition is clinically homogeneous with a simple well defined phenotype and diagnosis of affected subjects at operation is unequivocal. This reduces the risk of genetic heterogeneity and misdiagnosis. Ascertainment of a substantial family resource is facilitated by the high incidence, early presentation, and non-lethal nature of PS. By studying such high density families, in which there are mostly three or more affected subjects over several generations, it can be anticipated that the incidence of phenocopies is reduced and there is enrichment for cases with a major genetic contribution to aetiology.

Linkage analysis has been carried out using the lod score method. In the absence of definitive data from segregation analysis, arbitrary assumptions are necessary concerning inheritance parameters such as mode of inheritance, penetrance, and phenocopy rate. The most important assumption concerns the segregation of a locus with a major effect on the phenotype. Segregation analysis is compatible with a single major dominant gene of low penetrance. If inheritance is truly polygenic, it is unlikely that linkage to an individual locus can be detected.

Values for penetrance and phenocopy rate significantly affect the results of linkage analysis. If an adequate degree of incomplete pene- 
Pairwise lod scores between the PS trait and chromosome 9 marker loci. Penetrance 0.60 for male, 0.15 for female. $A$, autosomal dominant model of inheritance. $B$, autosomal recessive model of inheritance.

\begin{tabular}{|c|c|c|c|c|c|c|c|c|}
\hline & \multirow[b]{2}{*}{$\begin{array}{l}\text { Marker } \\
\text { locus }\end{array}$} & \multicolumn{6}{|c|}{ Lod score at recombination fraction of: } & \multirow[b]{2}{*}{$\begin{array}{c}\theta \text { at } \\
\operatorname{lod}=-2\end{array}$} \\
\hline & & 0.00 & 0.05 & $0 \cdot 10$ & $0 \cdot 20$ & $0 \cdot 30$ & $0 \cdot 40$ & \\
\hline A & $\begin{array}{l}\text { PS-D9S55 } \\
\text { PS-D9S111 } \\
\text { PS-D9S15 } \\
\text { PS-D9S12 } \\
\text { PS-D9S56 } \\
\text { PS- } D 9 S 59 \\
\text { PS- } A S S\end{array}$ & $\begin{array}{r}-12.015 \\
-12.406 \\
-9 \cdot 246 \\
-9.895 \\
-9 \cdot 320 \\
-10.307 \\
-11.803\end{array}$ & $\begin{array}{l}-4 \cdot 300 \\
-4 \cdot 836 \\
-3 \cdot 230 \\
-3 \cdot 365 \\
-3 \cdot 614 \\
-4 \cdot 687 \\
-4 \cdot 385\end{array}$ & $\begin{array}{l}-2.001 \\
-2.501 \\
-1.313 \\
-1.335 \\
-1.502 \\
-2.625 \\
-1.839\end{array}$ & $\begin{array}{r}-0.285 \\
-0.661 \\
0.093 \\
0.146 \\
0.077 \\
-0.751 \\
0.025\end{array}$ & $\begin{array}{r}0.144 \\
-0.092 \\
0.380 \\
0.413 \\
0.379 \\
-0.053 \\
0.378\end{array}$ & $\begin{array}{l}0.175 \\
0.051 \\
0 \cdot 267 \\
0 \cdot 266 \\
0 \cdot 255 \\
0 \cdot 127 \\
0 \cdot 237\end{array}$ & $\begin{array}{l}0 \cdot 10 \\
0 \cdot 11 \\
0 \cdot 07 \\
0.07 \\
0.08 \\
0 \cdot 11 \\
0 \cdot 09\end{array}$ \\
\hline B & $\begin{array}{l}\text { PS-D9S55 } \\
\text { PS-D9S111 } \\
\text { PS-D9S15 } \\
\text { PS-D9S12 } \\
\text { PS-D9S56 } \\
\text { PS-D9S59 } \\
\text { PS- } A S S\end{array}$ & $\begin{array}{l}-4.267 \\
-3.701 \\
-6.001 \\
-5.509 \\
-5.354 \\
-5.504 \\
-4.054\end{array}$ & $\begin{array}{l}-1.778 \\
-1.768 \\
-3.630 \\
-2.819 \\
-2.866 \\
-3.133 \\
-2.045\end{array}$ & $\begin{array}{l}-0.562 \\
-0.729 \\
-2.249 \\
-1.461 \\
-1.559 \\
-1.907 \\
-1.011\end{array}$ & $\begin{array}{r}0.331 \\
0.185 \\
-0.813 \\
-0.255 \\
-0.347 \\
-0.652 \\
-0.047\end{array}$ & $\begin{array}{r}0.364 \\
0.312 \\
-0.234 \\
0.070 \\
0.016 \\
-0.138 \\
0.198\end{array}$ & $\begin{array}{r}0.151 \\
0.135 \\
-0.038 \\
0.063 \\
0.047 \\
0.026 \\
0.141\end{array}$ & $\begin{array}{l}0.04 \\
0.04 \\
0.11 \\
0.07 \\
0.07 \\
0.09 \\
0.05\end{array}$ \\
\hline
\end{tabular}

trance is not built into the model of analysis, true linkage may be missed because apparently unaffected subjects will appear to be recombinants. ${ }^{25}$ Computer simulation experiments have shown that the source of the reduction in penetrance, that is, effects from other genes or environmental factors, has little influence on the outcome of linkage analysis. ${ }^{2627}$ By excluding unaffected subjects and setting the penetrance at an arbitrary low value, we have reduced the risk of missing a true linkage. Despite this stringent approach our available family resource retains substantial power. Application of SLINK analysis to these 20 families generated average lod scores of +4.95 and +2.19 at $\theta=0.20$ for the AD and AR models respectively.

The risk of locus heterogeneity obscuring linkage in a subset of families is present in any study which involves pooling data from more than one kindred. This risk can be reduced by confining the study to a homogeneous phenotype, but can never be eliminated even in mendelian disorders. HOMOG analysis did not show any significant heterogeneity in our families but of course a larger collection of families will be necessary to detect heterogeneity.

The reported association between PS and duplication of chromosome 9q11-q33 directed our initial attention to this region. Our data provide evidence against the existence of a major locus predisposing to PS within the region of chromosome $9 \mathrm{q} 11-\mathrm{q} 33$ under the specified models of inheritance. Exclusion data in linkage analysis of a complex disease trait must of course be interpreted with caution. However, it seems reasonable to adopt a pragmatic approach during any initial genome search, and to make more rigorous assumptions, such as very low penetrance, if a positive linkage does not emerge.

We are grateful to the Rockefeller Research Appeal Trust of University College London Medical School for financial support. This study would have been impossible without the cooperation of patients, their families and general practitioners, and the collaborating doctors including Dr R Bell (Banbury) and Dr A Day (Cheltenham). We thank Dr T Bishop, Dr N Morton, and Dr S Povey for helpful discussion.
1 Davison G. The incidence of congenital pyloric stenosis. Arch Dis Child 1946;21:113.

2 Dodge JA. Infantile hypertrophic pyloric stenosis in Belfast 1957-1969. Arch Dis Child 1975;50:171-8.

3 Cockayne EA. Congenital pyloric stenosis in first cousins. Lancet 1934;1:898.

4 Cockayne EA, Penrose LS. The genetics of congenital pyloric stenosis. Ohio f Sci 1943;43:1.

5 Carter CO. The inheritance of congenital pyloric stenosis. Br Med Bull 1961;17:251-4.

6 Mckeown T, MacMahon B, Record RG. The familial incidence of congenital pyloric stenosis. Ann Hum Genet 1951;16:260-81.

7 Metrakos JD. Congenital hypertrophic pyloric stenosis in twins. Arch Dis Child 1953;27:351-8.

8 Carter CO, Evans KA. Inheritance of congenital pyloric stenosis. $\mathcal{F}$ Med Genet 1969;6:233-54.

9 Dodge JA. Infantile hypertrophic pyloric stenosis-definition, physiology and genetics. In: The genetics and heterogeneity of common gastrointestinal disorders. New York: Academic Press, 1980:419-40.

10 Lalouel JM, Morton NE, MacLean CJ, Jackson L. Recurrence risks in complex inheritance with special regard to pyloric stenosis. ₹ Med Genet 1977;14:408-14.

11 Fried K, Aviv S, Nisenbaum C. Probable autosomal dominant infantile pyloric stenosis in a large kindred. Clin Genet 1981;20:328-30.

12 Kidd KK, Spence MA. Genetic analysis of pyloric stenosis suggesting a specific maternal effect. $\mathcal{f}$ Med Genet 1976;13:290-4.

13 Bianchi GP, Cantone P, Dalpra L, Simoni G. Trisomia parziale 9q: riscontro della sindrome in due sorelle. Minerva Pediatr 1986;38:109-14.

14 Hirschhorn K, Lucas M, Wallace I. Precise identification of various chromosomal abnormalities. Ann Hum Genet various chrom

15 Turleau C, de Grouchy J, Chavin-Colin F, et al. Partial trisomy 9q- chromosomal syndrome. Hum Genet 1976;34:151-4

16 Yamamoto Y, Oguro N, Nara T, Horita H, Niitsu N, Imaizumi $S$. Duplication of part of $9 q$ due to maternal $12 ; 9$ inverted insertion associated with pyloric stenosis. Am $\mathcal{f}$ Med Genet 1988;31:379-84.

17 Heyman A, Wilkinson W, Stafford JA, Helms M, Sigmon A, Weinberg T. Alzheimer's disease: a study of epidemiologic aspects. Ann Neurol 1984;15:335-41.

18 St George Hyslop PH, Tanzi RE, Polinsky RJ, et al. The genetic defect causing familial Alzheimer's disease maps on chromosome 21. Science 1987;235:885-90.

19 Miller SA, Dykes DD, Polesky HF. A simple salting out procedure for extracting DNA from human nucleated cells. Nucleic Acids Res 1988;16:1215.

20 Innis MA, Gelfand DH, Sninsky JJ, Thomas JW. PCR protocols-a guide to methods and applications. New York: Academic Press, 1990.

21 Povey S, Falk C, Smith M. Report of the committee on the genetic constitution of chromosome 9. HGM11. Cytogenet Cell Genet 1991;58:403-27.

22 Povey S, Smith M, Haines J, et al. Report on the First International Workshop on chromosome 9, Cambridge, UK, 22-24 March 1992. Ann Hum Genet 1992;56:167UK,

23 Kwiatkowski DJ, Henske EP, Weimer K, Ozelius L, Gusella JF, Haines J. Construction of a GT polymor phism map of human 9q. Genomics 1992;12:229-40.

24 Ott J. Analysis of human genetic linkage. Baltimore: Johns Hopkins University Press, 1991.

25 Lander ES. Mapping complex genetic traits in human. In: Genome analysis: a practical approach. Chapter 8. Oxford: IRL Press, 1988.

26 Greenberg DA, Hodge SE. Linkage analysis under "random" and "genetic" reduced penetrance. Genet Epidemiol 1989;6:259-64.

27 Vieland VJ, Hodge SE, Greenberg DA. Adequacy of singlelocus approximations for linkage analysis of oligogenic traits. Genet Epidemiol 1992;9:45-59. 